\title{
Energy in the Urban Environment: The Role of Energy Use and Energy Efficiency in Buildings
}

\author{
Mark D. Levine and Alan K. Meier ${ }^{1}$ \\ Lawrence Berkeley National Laboratory \\ University of California \\ Berkeley, California, USA
}

\section{Introduction}

A century ago, the world had many cities of which the greatest were magnificent centers of culture and commerce. However, even in the most industrialized countries at the time, only a tiny fraction of the people lived in these cities. Most people lived in rural areas, in small towns, in villages, and on farms. Visits to a great city were, for most of the population, uncommon events often of great fascination.

The world has changed dramatically in the intervening years. Now most of the industrial world lives in urban areas in close proximity to large cities. Industry is often located in these vast urban areas. As the urbanized zones grow in extent, they begin to approach one another, as on the East Coast of the United States.

The phenomenon of urbanization has moved to developing countries as well. There has been a flood of migrants who have left impoverished rural areas to seek economic opportunities in urban areas throughout the developing world. This movement from the countryside to cities has changed the entire landscape and economies of developing nations.

Importantly, the growth of cities places very great demands on infrastructure. Transportation systems are needed to assure that a concentrated population can receive food from the countryside without fail. They are needed to assure personal and workrelated travel. Water supplies must be created, water must be purified and maintained pure, and this water must be made available to a large population. Medical services - and a host of other vital services - must be provided to the population. Energy is a vital underpinning of all these activities, and must be supplied to the city in large quantities. Energy is, in many ways, the enabler of all the other services on which the maintenance of urban life depends.

In this paper, we will discuss the evolution of energy use in residential and commercial buildings. This topic goes beyond urban energy use, as buildings exist in both urban and non-urban areas. The topic does not address all energy use in cities - urban transportation is clearly important. However, buildings are the largest energy consumer

\footnotetext{
* This work was supported by the Assistant Secretary for Energy Efficiency and Renewable Energy, Office of Building Technology, State and Community Programs of the U.S. Department of Energy under Contract No. DE-AC03-76SF00098.
} 
in cities by a wide margin. (A typical Western home will consume at least five times as much energy as the typical car that services it.) As we note later, buildings consume more than one-third of total commercial energy globally. In developing countries, a large portion of energy use in buildings is in urban areas even though there are still large populations in rural areas. This is because vast quantities of non-commercial energy residue from plants, farm products, forests and dung from animals - are used to provide the services needed in households (primarily cooking and water heating) in many rural areas. Most of industrial energy use (which accounts for slightly more than $40 \%$ of global energy use) is outside of urban areas. Thus, any effort to address energy use in urban areas needs necessarily to deal with the energy use in buildings.

\section{What Are the Historical Trends in Energy Use in Buildings?}

During the period 1971 to 1990 , energy use in the world's buildings grew faster than energy use in any other sector. Energy use in commercial buildings grew at $3.5 \%$ per year. Residential energy use grew in the same period at $2.6 \%$ per year. Overall, energy use in buildings increased by $2.9 \%$ per year during the period. Transportation energy demand increased almost as fast, at $2.8 \%$ per year. Industrial energy demand grew at $2.1 \%$ per year. Overall energy demand grew at $2.5 \%$ per year during the period.

These global numbers obscure major differences among regions of the world. For the industrialized world, energy use in residential buildings increased at $1.4 \%$ per year while Asia-Pacific developing countries saw an annual increase of 5.2\%. ${ }^{2}$ After adjusting for increasing floor area of buildings, the energy intensity has actually declined for many countries (see Figure 1$)^{1}$.

\footnotetext{
"To limit the discussion somewhat, we will discuss three regions of the world: industrialized countries, Asia-Pacific developing countries, and the Soviet Union/Eastern Europe. The omitted regions are responsible for $11 \%$ of world energy use.
} 


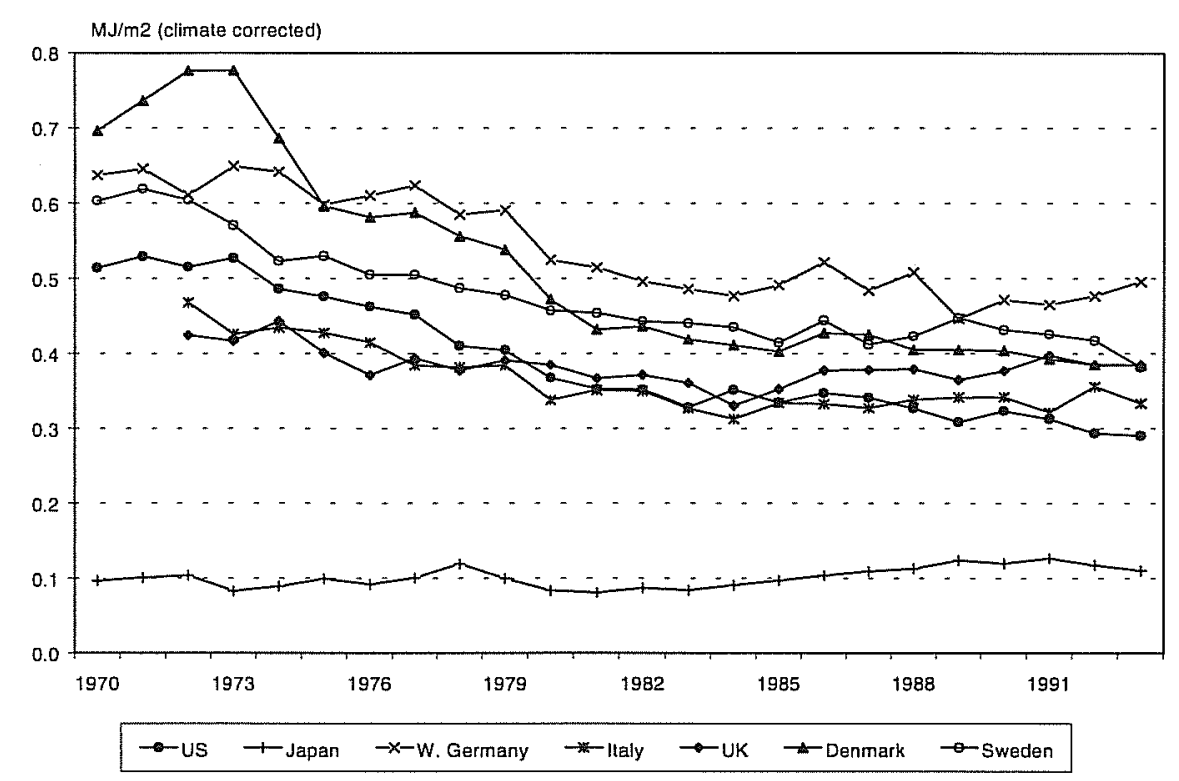

Figure 1. Trends in residential energy use in major developed countries.

Similarly for commercial buildings, annual energy use increased $2.5 \%$ (industrialized countries) and $7.8 \%$ (Asia-Pacific developing countries). During this period, the Soviet Union and Eastern Europe saw increases in building energy use intermediate between industrialized and Asian developing countries, with growth faster in the residential sector and slower in commercial buildings.

With the melting of the economies in the Soviet Union and Eastern Europe, growth in energy use in the period 1990-1995 became negative: -6.8\% per year for residential buildings and $-6.1 \%$ per year for commercial buildings. Growth in industrialized countries was $2.0 \%$ per year (residential) and $1.7 \%$ per year (commercial). Interestingly, during this period energy use in buildings in the Asia-Pacific developing countries was comparable to the previous period for residential buildings (4.8\% per year) and higher for commercial buildings reaching $9.0 \%$ per year. Much of this expansion was due to China, where construction activity was extraordinary during the period and the use of modern appliances in urban areas grew very rapidly.

\section{How Much Energy Will Buildings Use in the Future?}

There are many driving forces behind energy use in buildings. At the level of the nation, the growth of the economy and of population - including rate of urbanization - are of primary importance. At the level of the building, the choice of fuel and technology are important, as are the efficiency of the technology and the saturation of equipment that provides energy services.

For industrialized countries, it is reasonable to assume that future energy use will be somewhat similar to historical patterns, with changes driven in large measure by 
fluctuations in economic activity. Thus, the expectation of future energy demand growth in the near term in buildings might be on the order of 1.5 to $2 \%$ per year. Over time, this growth rate will probably decline as end-uses are increasingly saturated. It is very important to understand that such a growth rate is in no ways inexorable. As we will later observe, technologies are available that can reduce the growth of energy in buildings substantially, and at a net economic benefit to the consumer. There are also cultural and social determinants. But a future in industrialized countries with lower energy intensity and reduced energy growth rates will depend on decisions to pursue a range of policies.

For developing countries, the situation is much more complex. There are numerous unsatisfied energy demands, as represented by low but increasing saturation of many appliances. As people move up the economic ladder, they will move to larger and more modern dwellings and will purchase refrigerators, washing machines, water heaters, numerous small appliances, and in time in hot climates air conditioners. Population growth continues much higher in developing countries than in the rest of the world. The annual increase in urban population has been about $4 \%$ per year for developing countries from 1970 to 1990. Non-commercial fuels in rural households will, over time, be replaced by commercial fuels. Electricity will continue to grow to meet increasing demands that cannot be served by fossil fuels. Continued modernization of developing country economies will continue the pressure to build new commercial buildings.

For the countries in the former Soviet Union and Eastern Europe, energy demand in buildings in the near-term will be linked to the state of economic affairs. For the Soviet Union, it is unlikely that energy demand will increase for some years, until individuals and businesses can afford to pay for energy. It is also difficult to imagine that energy demand will decline much further, unless the economy unravels and reduced energy is part of a larger suffering of the population.

In summary, over the next ten to twenty years, in the absence of major changes, energy demand growth in buildings will probably remain at or somewhat lower than historic trends for industrialized countries. It will stagnate and in time (perhaps a decade, perhaps longer, depending on the pace of economic recovery) increase at a higher rate in the Soviet Union and Eastern Europe than industrialized countries.

For the developing world, the long-term (20-year) expectation is for continued and significant growth in energy use in both residential and commercial buildings. At present, because energy demand in the developing world is to a large degree driven by the Asia-Pacific developing world, there may be several years in which energy use in buildings increases little. But the authors of this paper expect this demand growth to return and expect continued pressure on energy systems from the buildings sector in the developing world. 


\section{Increasing Wealth and the Demand for Amenities}

A key determinant in forecasting energy demand is the levels of energy-related services sought by consumers. In Japan, increased wealth has led to, first, the introduction of an air conditioner in one room, later, in two rooms, and increasingly, in three rooms. Will "standard practice" in Japanese homes eventually converge to that in the United States where all rooms are cooled continuously during the warm season? If yes, then one can expect large increases in electricity demand in the upcoming twenty years. Japan is often the model for other East Asian countries, so similar trajectories are likely to occur in those countries, too. Rising levels of amenities have occurred for other appliances, such as refrigerators. Less than twenty years ago, the typical refrigerator in Japan was 170 liters. Now, 425 liter refrigerators are common and, in spite of striking efficiency improvements, their energy consumption is increasing. ${ }^{2}$ Other Asian countries are also following this trajectory.

But increasing wealth does not necessarily lead to an ever greater demand for amenities. Consumers can create lifestyles that include, or even require, something less. Two examples of energy-intensive services where the amenity has stabilized or even fallen presented are residential refrigeration in Europe and ventilation of commercial buildings in the United States.

In contrast to Japan, the size of a typical refrigerator in Europe has grown only modestly in spite of greatly increased wealth and the consumer's ability to buy larger units. Consumers appear satisfied with the present level of amenity because it is consistent with their lifestyle. In US commercial buildings, ventilation rates have been successfully reduced after cigarette smoking was eliminated. The high air change rates were no longer needed after the largest irritant was no longer being generated. This measure saved energy in the process of creating a more pleasant indoor environment. These kinds of lifestyle modifications are crucial elements of an economy that is both sustainable and attractive.

\section{What Technologies Exist that Can Reduce Energy Use in Buildings?}

Before proposing technologies to reduce building energy use, one must first determine how much energy is presently used in each end use. Figure 2 and Figure 3 show the major end uses of energy in residential and commercial buildings in the United States for $1990 .^{3}$ While these end-uses vary among many countries, the patterns of energy use in many other industrialized and developing countries are trending in the direction of U.S. energy use. As shown in Figure 2, space heating is almost half of U.S. residential energy use. This is followed by water heating, refrigeration, space cooling, and lighting. 


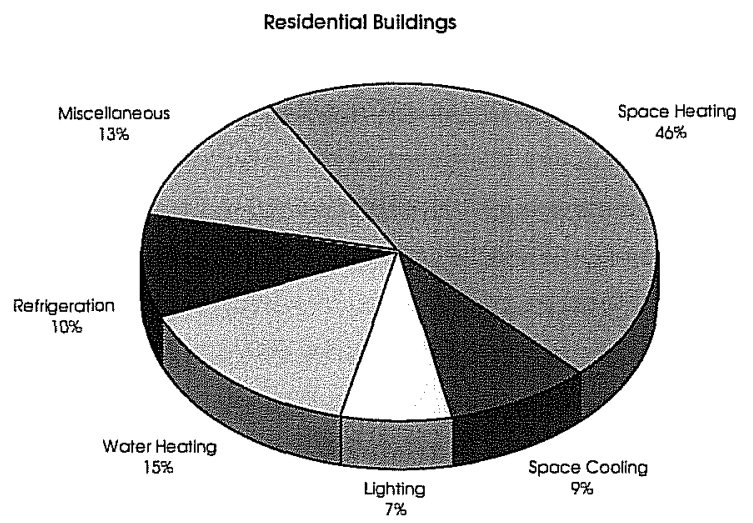

Figure 2. Breakdown of energy use by end use in the US residential sector.

Miscellaneous uses, constituting the third largest category of end uses, is the fastestgrowing end use and merits additional discussion later in the paper. For commercial buildings, lighting is the highest energy user, followed by miscellaneous equipment, and space heating. Cooling and ventilation are also important energy users in commercial buildings.

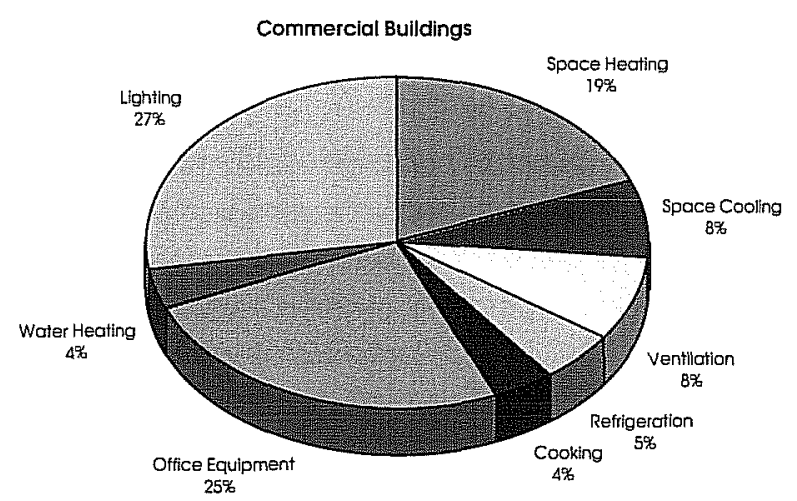

Figure 3. Breakdown of energy use by end use for US commercial buildings.

Technologies for increasing energy efficiency in buildings abound. It is not possible to discuss even a fraction of these technologies in a short paper. For residential buildings, we illustrate the opportunities for the largest energy user, space heating. There are four different strategies to reduce space heating energy use: (1) more efficient heating equipment, (2) reduction of heating loads, (3) minimizing losses in the distribution system that carries heat to the occupied portions of the building, and (4) employing smart controls to provide heat only when and where it is needed. ${ }^{4}$

There is a wide variety of efficient heating equipment. Highly efficient electric heat pumps are widely available. Gas furnaces above $90 \%$ efficiency are now widely available in markets where they are cost-effective. More expensive ground source heat 
pumps provide both heating and cooling at a very high efficiency. Efficiency gains in fans and motors improve overall heating efficiency.

There are even more ways to reduce heating loads: window coatings, reduction in infiltration, improved insulation in attics and roofs, insulation in floors and basements, passive solar design, etc.

Comparing a new residential building in the United States to typical construction practice in a climate with a significant heating load, easily $10 \%$ to $15 \%$ of the losses due to inefficient equipment and another $10 \%$ to $15 \%$ due to thermal distribution can be eliminated cost-effectively. Reductions in thermal loads can generally be much greater at cost-effective levels: perhaps 15 to $25 \%$ in many climates. These are highly approximate statements, but serve to illustrate the types of cost-effective energy savings possible in an industrialized country. Overall, applying all three measures, typical cost-effective savings could be in the range of $30 \%$ to $55 \%$ as compared to current practice.

\section{Supply Curves of Conserved Energy}

It is desirable to apply a systematic and quantitative assessment of energy savings potential. One approach is with a "supply curve of conserved energy." 5 Figure 4 is an example. Figure 4 was recently developed from very detailed data on all major (and many minor) end uses, described in the report "Scenarios of U.S. Carbon Emissions, 1990-2010)." 6 This supply curve describes the energy conservation potential in the US domestic sector, including appliances. This study investigated 304 different technologies, each represented by a step on the curve. The step's width shows the national energy saving potential. The step's height represents the technology's cost of conserved energy. The technologies are then ranked in order of increasing cost of conserved energy. The numbers above some of the steps are labels to help identify the most important measures. For example, step number 29 represents efficiency improvements to refrigerators. 


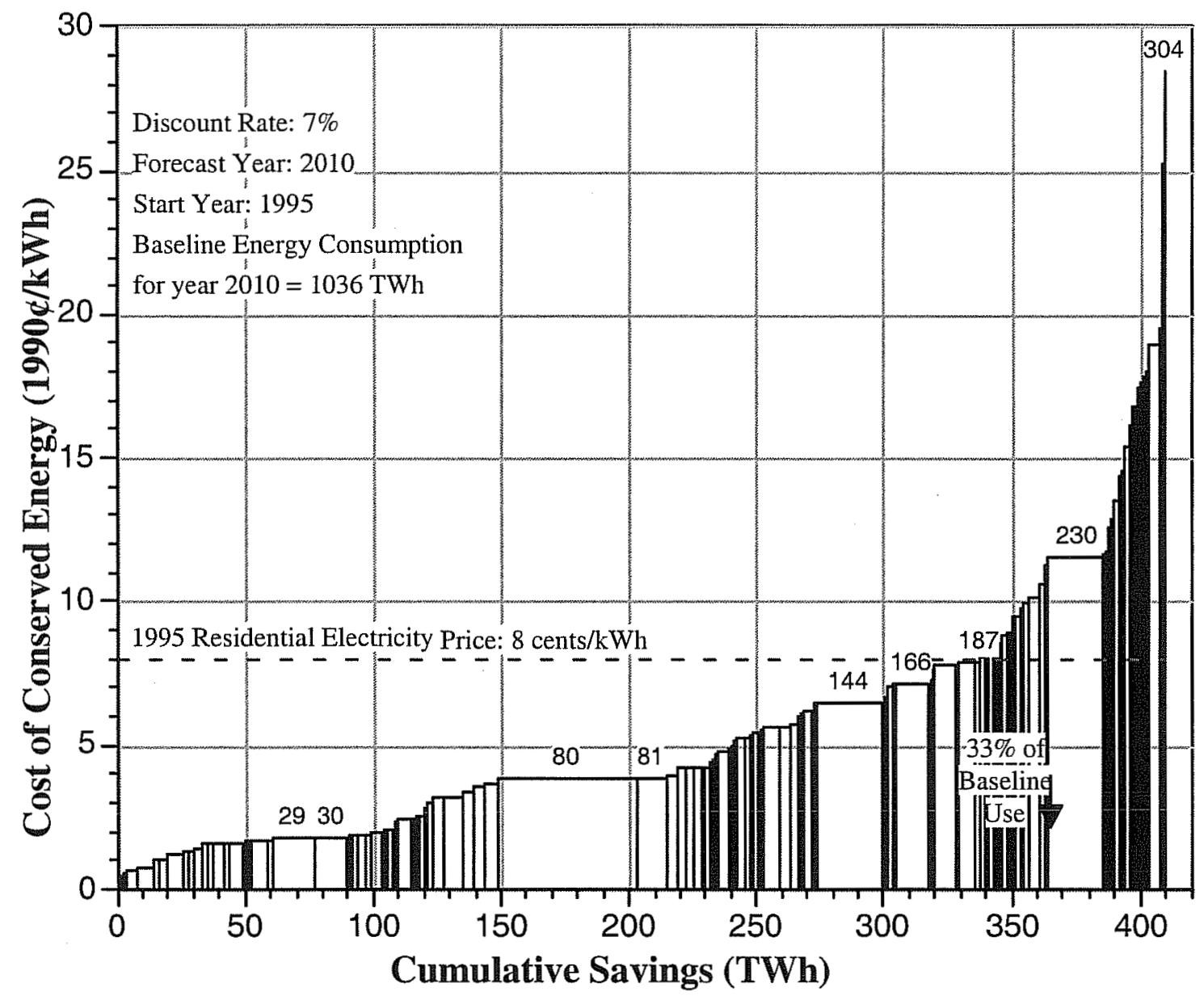

Figure 4. A supply curve of conserved energy for US homes.

The supply curve shows the overall potential for conservation as well as the costs. Technologies with costs of conserved energy less than the energy price are cost-effective. Note that roughly $33 \%$ of baseline energy use could be saved cost-effectively.

The upward bend in the supply curve is misleading about future opportunities to save energy. The supply curve of conserved energy suggests that, once the cheap measures have been accomplished, little more can be squeezed from the demand side. Our research suggests the opposite, that is, that the demand side is much more creative than this static curve implies. New opportunities for saving energy constantly appear because the services and amenities undergo redefinition.

Microwave ovens are an example of redefining a task (in this case, cooking). Traditionally, one had to heat the air in an oven which, in turn, gradually cooked the food. By heating the food directly (and only the food), cooking energy could be 
significantly reduced. Another example is ultra-pasteurized milk. This process permits the long-term storage of milk without energy-intensive refrigeration. Higher rates of recycling of energy-intensive materials can also redefine an industrial energy requirement. Nearly total recycling of aluminum beverage containers in the United States (implemented over a very short time span) has dramatically reduced the need for energy-intensive virgin aluminum production.

Our research suggests the next wave of energy savings will be from the application of more precise controls to thousands of activities. Microprocessors, linked to sensors, will save energy by limiting a device's operation to the times (and quantities) that the services are actually needed. These savings will appear in all sectors, from buildings to transportation, and in nearly all end uses.

\section{What Policies Can Promote Energy Efficiency?}

In the authors' view, there are compelling reasons to reduce growth of energy use - but not of the services that energy provides - in buildings and other sectors. Such reductions are desirable in reducing both local and global pollution. Such reductions can yield economic benefits to consumers in the form of lower energy bills and to nations in the form of reduced capital investments in energy supply systems.

The issue is what policies can be used and have they worked.

Addressing the question of "have policies worked" is a bit beyond the scope of this paper. But an example of a policy that works is worthwhile. In the United States in the middle 1970 s, the typical refrigerator consumed 1800 to 2000 kilowatt-hours per year. ${ }^{7}$ Manufacturers had no plans to alter the energy efficiency of such refrigerators. Virtually no one believed that a refrigerator could be built that consumed less than 1000 kilowatthours per year throughout the early 1980s. The United States, with considerable difficulty, put into place a series of standards on appliances, including refrigerators. Most of these standards took effect from the late 1980s to the present. (Recently, similar efficiency standards for refrigerators have been introduced in the European Union and Japan.) The current standard on new refrigerators calls for on the order of 500 kilowatthours per year. The entire reduction in energy intensity has been shown to be costeffective to the consumer and to society, as required by the federal appliance energy efficiency standards. The savings to consumers are in the tens of billions of dollars.

Thus, one of the types of policies is regulatory measures, as illustrated by appliance standards. Such standards need to have well-defined test procedures to assess energy use of the appliances. They need to be evaluated on economic grounds to ensure that they are cost-effective. They often require a strong political will to be put into practice. As noted, they can be highly effective.

Building codes are another type of regulatory measure. Such codes can specify building practices that promote energy efficiency. Such codes also need to be developed with 
assurance that they are cost-effective. They can be implemented by building code inspectors. Such codes can be mandatory or voluntary. Their goal is to change overall practice of builders. In many cases, the codes are rendered more effective if combined with one or more of the programs described below.

A second approach involves market programs of various types. Examples include government programs that achieve voluntary agreement of parties to implement costeffective energy efficiency, procurement programs in which large purchasers specify energy efficiency criteria, incentives for manufacturers or consumers based on producing or purchasing energy efficient products, and utility demand-side management programs that use the utility as the purveyor of energy efficiency products. Recently, the term "market transformation" has come into widespread use as a description of a market program that is designed to create sustained demand in the market for energy-efficient products.

A third approach, especially needed in many developing countries, involves removing subsidies from energy prices. Such subsidies distort investments, and greatly increase the already significant difficulty of inducing consumers to invest in energy efficiency. Experience has shown that price alone is insufficient to cause the majority of costeffective energy efficiency measures to be adopted. However, without energy prices that reflect costs - ideally including externalities, but rarely so - energy efficiency investments are rendered very difficult.

A fourth approach involves research and development to produce advances in energy efficiency in buildings. Improved lighting systems, advanced window glazings, highperformance insulation, improved design (including solar design), tools to monitor and control energy use in commercial buildings, more efficient heating and cooling equipment and appliances, fuel cells for stationary applications, advanced electronics to operate buildings more efficiently, are examples of needed R\&D for buildings.

\section{The Exciting Uncertainties in Energy Demand and Efficiency}

We are continually surprised by the twists and turns in the demand for energy, even in the technologies that we would expect to be fairly predictable. We briefly describe three examples of unexpected trends and linkages.

"Leaking Electricity". An increasing number of appliances continue to consume electricity even when switched off or not performing their central function. ${ }^{8}$ Each appliance (such as a television, VCR, cordless phone, etc.) draws $1-25 \mathrm{~W}$ in its standby mode. It is easy to dismiss this use yet, because there are hundreds of millions of these devices, the cumulative consumption is huge and may already be responsible for as much as $1 \%$ of global $\mathrm{CO}_{2}$ emissions. An international effort is now underway to restrain leaking electricity to $1 \mathrm{~W}$ per device. 
Urban Heat Islands and Surface Albedo. Air pollution is a common problem in large cities. The rates of formation of photochemical smog are strongly dependent on the air temperature, so smog levels are worst during summers and periods of high temperatures. The urban heat island phenomenon exacerbates the effect by further raising urban air temperatures. These periods also coincide with maximum air conditioning demand. Recent research suggests that raising the albedo of building and surrounding surfaces can reduce air conditioning demand in buildings while lowering urban air temperatures. ${ }^{9}$ The lower urban air temperatures-even though just a few degrees-can sharply reduce rates of smog formation. This research demonstrates the interconnection between energy use, urban form, and the environment.

The Decline in Space Heating and the Rise of Miscellaneous End Uses. Government programs in the United States (and Europe) have successfully reduced the energy consumed to supply space heating needs in homes. Overall energy use-especially electricity-has not declined as much as expected because a host of "miscellaneous" end uses has arisen. These uses include home electronics, water beds, heated toilet seats, dehumidifiers, microwave ovens, air-to-air heat exchangers, spas, aquariums, and much more. Altogether, these miscellaneous uses represent as much as $20 \%$ of residential electricity demand and appear to be growing faster than any other category. ${ }^{10} \mathrm{~A}$ completely new set of programs and policies will be needed to address it.

\section{Conclusions}

Energy use in cities covers a wide range of activities, but the energy used by buildings, and the equipment inside them, is the largest single component. This energy demand is important because it is large, but also because it is growing faster than other sectors. Yet the overall growth rates conceal tremendous regional variations caused by rapid economic growth, restructuring of national economies, and rising demands for energyrelated services. We believe that growth will continue at a rapid rate, yet tempered by economic turmoil in some critical areas, such as in Russia and East Asia.

There are other determinants to the demand for energy besides increasing wealth. The most important is the level of services and amenities demanded by consumers. We presented two contrasting examples of increasing wealth and demand for services. It is important to study these relationships because they affect the long-term equilibrium demand for energy. Furthermore, de-coupling increasing wealth and energy demand is an essential step towards any form of a sustainable economy.

Improved efficiency of energy use is another means of de-coupling increasing wealth from increasing demand for energy. We presented four energy-saving strategies for a house, that is, increasing the efficiency of energy conversion and delivery, reducing loads, and wider use of controls. These strategies apply to a wide range of energyconsuming activities and can potentially sharply reduce energy consumption. In addition, we described ways in which the tasks are re-defined, leading to further reductions in energy use. The supply curve of conserved energy is a useful way to show the limits with 
the existing approaches but does not indicate when the redefinition of task will lead to further savings.

Energy efficiency will often happen as a matter of course and adjustment to market conditions. Nevertheless, policies can be developed to accelerate the pace, especially when market failures impede its adoption. We described a series of successful policies that have caused significant efficiency improvements.

Finally, we presented three examples of the kinds of surprises and linkages encountered when studying and forecasting building energy use. These examples demonstrate the dynamic nature of energy demand and the value of constant attention to the topic.

\section{References}

${ }^{1}$ Schipper, Lee (1997), Indicators of Energy Use and Efficiency, Paris (France). International Energy Agency.

${ }^{2}$ Nakagami, H. and B. Litt (1997). “Appliance Standards in Japan.” Energy and Buildings 26(1): 69-79.

${ }^{3}$ U.S. Congress, Office of Technology Assessment. (1992). Building Energy Efficiency. Washington, D.C., U.S. Government Printing Office.

${ }^{4}$ Meier, A. K. (1997). 'Toward More Efficient Energy Use Through Demand-Side Management." Energy and Resources (Japanese) 18(3): 211-217.

${ }^{5}$ Meier, A. K., J. Wright, et al. (1983). Supplying Energy Through Greater Efficiency. Berkeley, CA, University of California Press.

${ }^{6}$ Interlaboratory Working Group. 1997. "Scenarios of U.S. Carbon Reductions: Potential Impacts of Energy-Efficient and Low-Carbon Technologies by 2010 and Beyond." Oak Ridge, TN. Oak Ridge National Laboratory. ORNL-444 September.

${ }^{7}$ Geller, H. (1997). "National Appliance Efficiency Standards in the USA: Cost-Effective Federal Regulations." Energy and Buildings 26(1): 101-109.

${ }^{8}$ Meier, A., K. Rosen, et al. (1998). Reducing Leaking Electricity to 1 Watt. ACEEE Summer Study on Energy Efficiency in Buildings, Pacific Grove, CA, American Council for An Energy-Efficient Economy. Also see http://eetd.lbl.gov/leaking

${ }^{9}$ Taha, H. (1997). "Urban Climates and Heat Islands: Albedo, Evapotranspiration, and Anthropogenic Heat." Energy and Buildings 25(2): 99-103.

${ }^{10}$ Sanchez, M. C., J. G. Koomey, et al. (1998). "Miscellaneous Electricity in US Homes: Historical Decomposition and Future Trends." Energy Policy 26(8): 585-593. 